\section{PENGARUH SUHU VULKANISASI TERHADAP \\ SIFAT TEGANGAN PUTUS, PERPANJANGAN PUTUS DAN KETAHANAN SOBEK KOMPON SOL KARET}

Oleh : Prayitno

\section{ABSTRACT}

One of the processes steps for producing rubber sole is vulcanisation proess. This process is carried out by using pressed moulding methods in which rubber compound was heated and pressed in the mould of rubber sole at certain ime and temperature. The aim of this research is to know the influence of the temperature used for vulcanization for the tensile strength, elongation and tearing strength properties of the rubber sole compound. Temperature vulcanisation used for the research was varied at $140^{\circ} \mathrm{C}, 150^{\circ} \mathrm{C}, 160^{\circ} \mathrm{C}$ and $170^{\circ} \mathrm{C}$. The at valcanisation at $140^{\circ} \mathrm{C}$, give the highest properties in tensile strength, elongation and tearing strength, those are : $113,70 \mathrm{~kg} / \mathrm{cm}^{2} ; 326,60 \%$ and $107,00 \mathrm{~kg} / \mathrm{cm}^{2}$ respectively. Increasing temperature vulcanisation cause decreasing those physical properties.

\section{INTISARI}

Salah satu tahapan proses pada pembuatan sol karet adalah proses vulkanisasi. Proses ini dilakukan dengan menggunakan metoda cetak tekan dimana kompon karet dipanaskan dan ditekan dalam cetakan sol karet pada temperatur dan waktu tertentu. Tujuan dari penelitian ini adalah untuk mengetahui pengaruh temperatur yang digunakan untuk vulkanisasi pada sifat kuat tarik, kemuluran dan kuat sobek dari kompon sol karet. Temperatur vulkanisasi pada penelitian ini adalah divariasi pada suhu $140^{\circ} \mathrm{C} 150^{\circ} \mathrm{C}, 160^{\circ} \mathrm{C}$ dan $170^{\circ} \mathrm{C}$. Hasil penelitian menunjukkan bahwa vulkanisasi dengan suhu $140^{\circ} \mathrm{C}$ akan memberikan sifat sifat kuat tarik, kemuluran dan kuat sobek yang terbaik dari kompon sol karet, yaitu : $113,70 \mathrm{~kg} / \mathrm{cm}^{2} ; 326,60 \%$ dan $107,00 \mathrm{~kg} / \mathrm{cm}^{2}$. Kenaikan temperatur vulkanisasi akan menurunkan sifat-sifat fisika tersebut

\section{PENDAHULUAN}

Sol karet merupakan bawahan sepatu yang berhubungan langsung dengan tanah, terbuat dari bahan baku karet, baik karet alam mapun karet sinetis atau campuran dari keduanya. Sol karet dibuat melalui tahapan proses me-

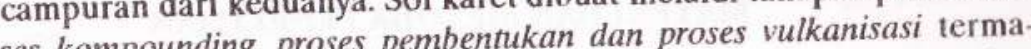
liputi proses kompounding, proses pembentukan dan proses wukanisasi termasuk dalam Proses Kompounding adalah penimbangan bahan sesuai dengan fo mulasi yang telah ditentukan, proses mastilasi yaitu proses untuk melunakkan bahan baku karet sehingga menjadi plastis untuk memudahkan pencampuran bahan-bahan pembantu dan proses pencampuran yaitu memasukkan bahanbahan pembantu dalam karet.

pencampuran. Suhu yang digunakan untuk pencampuran dengan two roll mill ( digunakan untuk pencampuran dengan two roll mill $70 \pm 5^{\circ} \mathrm{C}$, sedang dengan Banburry Mixer berkisar $110-125^{\circ} \mathrm{C}$, dengan total waktu pencampuran pada two roll mill 24 menit sedang pada bonburry mixer 13 menit.

Pada proses vulkanisasi untuk sol dilakukan dengan sistem cetak tekan, dimana kompon karet dicetak pada cekatan yang bentuknya telah disesuaikan dengan produk jadinya, kemudian dilakukan penekanan dan pemanasan. Proses vulkanisasi dipengaruhi oleh komposisi bahan serta suhu. Penggunaan jenis bahan pencepat tertentu pada komposisi kompon akan mempengaruhi waktu vulkanisasi, sedangkan pengaruh suhu terhadap proses vulkanisasi adalah seperti pengaruh suhu pada reaksi-reaksi kimia pada umumnya. Dimana kenaikkan $10^{\circ} \mathrm{C}$ akan mempercepat reaksi dua kali. Penggunaan panas akan mempercepat proses vulkanisasi, akan tetapi di lain pihak panas akan merusakkan molekul karetnya. Teori vulkanisasi dari Kelly mengemukakan bahwa karet adalah Poly phase system $\left(\mathrm{C}_{5} \mathrm{H}_{8 / n}\right)$, pada tiao-tiap unit terdapat satu ikatan rangkap, perlakuan panas dan meka ${ }^{\text {iz }}$ couvorung mematahkan atau memecah unit besar dan maret. Pada proses vulkanisasi karet dipanaskan bersama-sama dengan sulphur, sulphur akan dilarutkan dalam molekul karet. Sulphur dilarutkan dalam karet dalam bentuk molekul aktif, yang oleh kerja accelerator akan diubah kebentuk atom aktif yang kemudian bereaksi dengan molekul karet pada ikatan rangkapnya. Perlakuan panas akan menimbulkan efek yang bertentangan, disatu pihak panas akan mengaktifkan sulphur dilain pihak panas akan merusakkan molekul-molekul karet. Sehingga sifat dan kelakuan karet akan tergantung pada kecepatan dalam mana sulphur dibuat aktif. Jika pengaktifan sulphur cepat maka karet akan divulkanisasi dan diperkuat sebelum pemecahan terjadi, akan tetapi bila pengaktifannya lambat karet akan hancur sebelum tervulkanisasi.

Atas dasar tersebut maka perlu dilakukan penelitian sejauh mana suhu vulka- 
sasi akan berpengaruh terhadap sifat fisika kompon karet, terutama sekali da sifat kuat tarik, kemuluran dan kuat sobek yang merupakan sifat-sifa sar karet.

\section{MATERI DAN METODA PENELITIAN}

\section{ateri Penelitian}

Bahan-bahan yang dipergunakan untuk penelitian :

R S S II, Karet reklaim, Zn O, Carbon Black, Asam Stearat, Mineral rubber, P B N, M B T, M B T S, T M T, Sulphur.

Alat-alat yang digunakan :

Timbangan, Two roll mill, Hydraulic press, Alat uji curetime. Alat pembuat contoh uji, Alat uji kuat tarik.

\section{etoda Penelitian :}

\section{Metoda pembuatan kompon.}

Metoda yang digunakan pada penelitian ini adalah dengan mengadakan percobaan pembuatan kompon karet dengan perbandingan tertentu dan bahan pengisi yang disesuaikan untuk kompon sol sepatu. Untuk setiap kompon 300 gram, dengan komposisi sebagai berikut.

Komposisi Bahan :

$\begin{array}{lrllrl}\text { RSS } & 100 & \text { bagian. } & \text { Carbon Black } & 60 & \text { bagian. } \\ \text { Reclaim rubber } & 40 & \text { bagian. } & \text { MBT } & 0,5 & \text { bagian. } \\ \text { Asam stearat } & 2 & \text { bagian. } & \text { MBTS } & 0,5 & \text { bagian. } \\ \text { ZnO } & 5 & \text { bagian. } & \text { TMT } & 0,2 & \text { bagian. } \\ \text { PBN } & 1 & \text { bagian. } & \text { Sulphur } & 2 & \text { bagian. }\end{array}$

Pembuatan kompon dilakukan dengan menimbang semua bahan-bahan sesuai dengan formulasi, kemudian dengan menggunakan alat two roll mill, dilakukan penggilingan, mula-mula karet alam RSS digiling sampai plastis, kemudian tambahkan karet reclaimnya, digiling sampai plastis dan tercampur sempurna dengan karet alamnya. Kemudian berturut-turut tambahkan mineral rubber, PBN, asam stearat giling sampai homogen. Kemudian ZnO, Carbon Black digiling sampai homogen, kemudian tambahkan MBT, MBTS dan TMT digiling homogen, terakhir tambahkan sulphur dan digiling sampai homogen. Selama penggilingan temperatur tidak boleh lebih dari $60^{\circ} \mathrm{C}$ dan se- belum vulkanisasi, kompon dikondisikan dulu selama 24 jam.

Untuk proses vulkanisasinya dilakukan dengan menggunaan suhu yang divariasi : $140^{\circ} \mathrm{C}, 150^{\circ} \mathrm{C}, 160^{\circ} \mathrm{C}, 170^{\circ} \mathrm{C}$. Untuk mengetahui waktu vulkanisasi optimum dilakukan pengujian "Curetime". Kompon yang sudah diketahui pemasakannya kemudian dibuat slab untuk pengujian dengan ketebalan $3 \mathrm{~mm}, 5 \mathrm{~mm}, 10 \mathrm{~mm}$, dalam mesin Hydraulic Press. Tekanan digunakan tetap $150 \mathrm{~kg} / \mathrm{cm}^{2}$.

Waktu vulkanisasi dihitung saat mulai penekanan. Setelah waktu vulkanisasi selesai, diinginkan plat pemanas dengna air mengalir sampai suhu $60^{\circ} \mathrm{C}$ $70^{\circ} \mathrm{C}$, kemudian tekanan dilepas dan slab dikeluarkan dari hydraulic press dan cekatan. Kondisikan selama 24 jam sebelum pengujian.

\section{b. Metoda Pengujian :}

Untuk mengetahui sifat-sifat fisis kompon karet yang divulkanisasi dengan suhu yang berbeda-beda, dilakukan pengujian-pengujian fisika untuk jenis uji Tegangan putus, Perpanjangan putus dan ketahanan sobek. Ketiga sifatsifat fisika tersebut merupakan sifat karet yang kemungkinan akan dipengaruhi oleh penggunaan suhu vulkanisasi.

- Uji tegangan putus dan perpanjangan putus :

Pengujian dilakukan dengan menggunakan alat uji kekuatan tarik. Contoh uji berupa slab setebal $3 \mathrm{~mm}$ dengan menggunakan pisau pons bentuk dayung. Ukur tebal serta lebar pada bagian sempit pada tiga (3) tempat, hasilnya kemudian dirata-rata. Dengan menggunakan mesin uji kekuatan tarik contoh uji dipasang pada alat uji dengan jarak jepitan $50 \mathrm{~mm}$. Lakukan penarikan hingga contoh uji putus. Catat beban serta perpanjangan saat putus.

Tegangan Putus $=\frac{\mathrm{F}}{\mathrm{t} \text { W }} \mathrm{kg} / \mathrm{Cm}^{2}$

Dimana :

$\mathrm{F}=$ beban maksimum saat putus $(\mathrm{kg})$

$\mathrm{t}=$ tebal $(\mathrm{Cm})$

$\mathrm{W}=\operatorname{lebar}(\mathrm{Cm})$

Perpanjangan Putus $=\frac{\mathrm{L}_{1}-\mathrm{LO}_{\mathrm{O}}}{\mathrm{LO}_{\mathrm{O}}} \times 100 \%$

Dimana :

Lo = Panjang putus sebelum ditarik $(\mathrm{Cm})$. $\mathrm{L}_{1}=$ Panjang sesudah ditarik $(\mathrm{Cm})$. 


\section{Uji Ketahanan Sobek.}

Uji ketahanan sobek dilakukan dengan menggunakan alat uji kuat tarik. Contoh uji dengan bentuk empat persegi panjang dengan ukuran 1 X 10 $\mathrm{Cm}$, pada bagian tengah sejajar potongan melintang daerah lebar dibuat sobekan dengan panjang $0,5 \mathrm{Cm}$. Setelah diukur tebal bagian yang disobek dilakukan penarikan.

Kuat Sobek $=\frac{F}{\mathrm{t} \times \mathrm{W}} \mathrm{kg} / \mathrm{Cm}^{2}$

Dimana :

$\mathrm{F}=$ beban maksimum saat putus $(\mathrm{kg})$

$\mathrm{t}=\mathrm{tebal}(\mathrm{Cm})$

$\mathrm{W}=$ lebar setelah sobekan awal $(\mathrm{Cm})$

Metoda Analisa Data.

Dari masing-masing data uji yang didapat kemudian dilakukan analisa statis tik dengan metoda CRD dari tabel anova. F akan dapat diketahui apakah ada perbedaan nyata pada sifat-sifat tegangan putus, perpanjangan putus dan

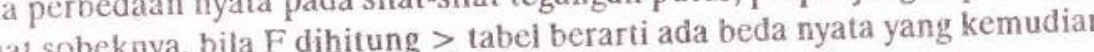
dilanjutkan ke perhitungan LSD untuk mengetahui letak perbedaannya.,

\section{HASIL, PENELITIAN DAN PEMBAHASAN}

Hasil uji rata-rata terhadap tegangan putus, perpanjangan putus dan keanan sobek adalah seperti pada tabel berikut

abel 1 : Hasil Uji Tegangan Putus, Perpanjangan Putus dan Kuat Sobek.

\begin{tabular}{|l|c|c|c|c|c|}
\hline \multirow{2}{*}{ Jenis uji } & \multirow{2}{*}{ Satuan } & \multicolumn{4}{|c|}{$\mathrm{S} \mathrm{u} \mathrm{h} \mathrm{u}$} \\
\cline { 3 - 6 } & & $140^{\circ} \mathrm{C}$ & $150^{\circ} \mathrm{C}$ & $160^{\circ} \mathrm{C}$ & $170^{\circ} \mathrm{C}$ \\
\hline Tegangan putus & $\mathrm{kg} / \mathrm{cm}^{2}$ & 113,70 & 105,68 & 104,80 & 105,82 \\
Perpanjangan putus & $\%$ & 323,60 & 273,60 & 282,0 & 297,60 \\
Ketahanan Sobek & $\mathrm{kg} / \mathrm{cm}^{2}$ & 107,00 & 94,61 & 92,02 & 90,02 \\
\hline
\end{tabular}

Hasil analisa statistik terhadap sifat tegangan putus, perpanjangan putus dan retahanan sobek didapat anova seperti tabel 2,3 dan 4.
Tabel 2 : Anova untuk uji Tegangan Putus.

\begin{tabular}{|c|c|c|c|c|c|}
\hline \multicolumn{1}{|c|}{ S.V } & J.F. & SS & MS & F cal & F 5\% \\
\hline Perlakuan & 3 & 259,123 & 86,374 & & \\
Error & 16 & 110,086 & 6,881 & & 3,24 \\
\hline Total & 19 & & & & \\
\hline
\end{tabular}

Dari tabel anova tersebut di atas terlihat F cal lebih besar dari pada F $5 \%$ tabel, berarti ada beda nyata pada sifat-sifat tegangan putus kompon karet yang dibandingkan. Untuk mengetahui letak perbedaannya maka dilanjutkan dengan perhitungan LSD. Dari perhitungan didapat LSD $5 \%=3,5171$ perbedaan nyata. Sifat tegangan putus terjadi pada kompon yang divulkanisasi dengna suhu $140^{\circ} \mathrm{C}$ dengan kompon yang divulkanisasi pada suhu $150^{\circ} \mathrm{C}, 160^{\circ} \mathrm{C}$ dan $170^{\circ} \mathrm{C}$. Sedang kompon yang divulkanisasi dengan suhu suhu $150^{\circ} \mathrm{C}, 160^{\circ} \mathrm{C}$ dan $170^{\circ} \mathrm{C}$ masing-masing tidak menunjukkan perbedaan nyata. Kompon yang divulkanisasi pada suhu $140^{\circ} \mathrm{C}$ memberikan sifat tegangan putus yang lebih besar dari kompon yang lebih besar dari kompon yang divulkanisasi pada suhu $150^{\circ} \mathrm{C}, 160^{\circ} \mathrm{C}$ dan $170^{\circ} \mathrm{C}$.

Hal tersebut dapat diartikan bahwa pada suhu $140^{\circ} \mathrm{C}$ pengaktifan Sulfur belum diikuti dengan pemecahan molekul-molekul karet.

Tabel 3 : Anova untuk perpanjangan putus.

\begin{tabular}{|l|c|c|c|c|c|}
\hline \multicolumn{1}{|c|}{ S.V } & J.F. & SS & MS & F cal & F 5\% \\
\hline Perlakuan & 3 & 7245,6 & 2415,2 & & \\
Error & 16 & 2377,6 & 148,6 & & 3,24 \\
\hline Total & 19 & 9623,2 & & & \\
\hline
\end{tabular}

Dari tabel anova untuk perpanjangan putus terlihat bahwa $\mathrm{F}$ hitung lebih besar dari pada F 5\% tabel, hal ini berarti ada beda nyata pada sifat perpanjangan putus yang dibandingkan. 
udian dilanjutkan pada perhitungan LSD, didapat untuk LSD $5 \%=16$, Dari notasi LSD 5\% dapat diketahui kompon yang divulkanisasi dengan $140^{\circ} \mathrm{C}$ memberikan kemuluran yang paling besar dibandingkan dengan $140^{\circ} \mathrm{C}$ memberikan suhu $150^{\circ} \mathrm{C}, 160^{\circ} \mathrm{C}$ dan $170^{\circ} \mathrm{C}$. Sedang kompon engan suhu $150^{\circ} \mathrm{C}, 160^{\circ} \mathrm{C}$ dan $170^{\circ} \mathrm{C}$ masing-masing tidak divulkanisasi dengan suhu $150^{\circ} \mathrm{C}, 160^{\circ} \mathrm{C}$ dan unjukkan perbedaan nyata.

pon yang divulkanisasi pada suhu $150^{\circ} \mathrm{C}$ tidak menunjukkan beda nyata desuhu $160^{\circ} \mathrm{C}$ tetapi menunjukkan beda nyata dengan suhu $170^{\circ} \mathrm{C}$. ikkan suhu vulkanisasi akan menurunkan sifat kuat tarik kompon karet.

el 4 : Anova untuk kekuatan sobek.

\begin{tabular}{|l|c|r|r|r|r|}
\hline S.V & J.F. & \multicolumn{1}{c|}{ SS } & MS & F cal & F 5\% \\
\hline rlakuan & 3 & 861,81 & 287,27 & & \\
\hline ror & 16 & 66.09 & 4,13 & & 3,24 \\
\hline
\end{tabular}

i tabel anova untuk kekuatan sobek terlihat $\mathrm{F}$ hitung lebih besar dari pada $\mathrm{F}$ tabel, kemudian dilanjutkan pada perhitungan LSD, didapat untuk LSD $5 \%$ 2,73. Dari perhitungan LSD diketahui kekuatan sobek pada perlakuan de2 $140^{\circ} \mathrm{C}$ berbeda nyata dan lebih besar dibandingkan dengan kompon in suhu $140^{\circ} \mathrm{C}$ berbeda nyata dan tebi besan $170^{\circ} \mathrm{C}$. Di atas suhu $140^{\circ} \mathrm{C}$ perg divulkanisasi pada suhu $150^{\circ} \mathrm{C}, 160^{\circ} \mathrm{C}$ dan $170^{\circ} \mathrm{C}$ laan nyata kuat sobek baru terjadi pada interval suhu $20^{\circ} \mathrm{C}$, jadi pada suhu ${ }^{\circ} \mathrm{C}$ dengan suhu $170^{\circ} \mathrm{C}$. Hal tersebut dapat diartikan hahwa pemecahan moul-molekul karet akan berbeda nyata pada interval suhu $20^{\circ} \mathrm{C}$.

\section{KESIMPULAN}

ri hasil penelitian dapat disimpulkan :

Kenaikkan suhu vulkanisasi akan menurunkan sifat kuat tarik, perpanjangan putus serta kuat sobek kompon sol karet.

Vulkanisasi dengan suhu $140^{\circ} \mathrm{C}$ memberikan sifat-sifat fisika yang lebih baik dibanding dengan vulkanisasi pada suhu $150^{\circ} \mathrm{C}, 160^{\circ} \mathrm{C}$ dan $170^{\circ} \mathrm{C}$.

\section{DAFTAR PUSTAKA}

1. Barron H, Modern Rubber Chemistry, D Van Mostrad Inc, New York, USA.

2. Morton M, Rubber Technology, Reinhold Publishing Co, 13 th Edition, New York.

3. Suntoyo Ir, Experimental Design, Fakultas Pertanian UGM, Yoyakarta.

4. Suwarti S, Pedoman Pengujian Sifat-sifat Fisika Barang Jadi Karet, Balai Penelitian Perkebunan, Bogor. 